\title{
Original
}

\section{Comparison of Joint Space Width Determinations in Grade I and II Knee Osteoarthritis Patients Using Manual and Automatic Measurements}

\author{
Sugiyanto Sugiyanto ${ }^{* * 0}$, Fatimah Fatimah², Wahyu Setia \\ Budi $^{3}$, Ari Suwondo 4 , Hadi Suyanto 5
}

\begin{abstract}
Background: Examination of the knee to assess the narrowing of the joint gap or joint space width (JSW) is commonly done by manually checking radiographs and measuring the JSW using a ruler.

Objective: This study aims to compare manual and automatic measurements with the diagnosis of grade I and grade II knee osteoarthritis.

Material and Methods: In this cross-sectional study, 40 patients with the criteria for primary osteoarthritis $(\mathrm{OA})$, aged 46 to 65 years old had knee OA grades of either I or II. The knee image was evaluated by a computer program and a radiologist manually viewing and measuring the JSW joint gap using a ruler.

Results: The results showed there were no differences in the measurement of JSW medial and JSW lateral manually in grade I and grade II knee OA, at $\mathrm{p}=0.605$ and $\mathrm{p}=0.344$, respectively. Whereas in the automatic measurements, there was a difference between JSW medial and lateral JSW in grade I and grade II knee OA, each with $p<0.001$. The manual JSW measurement between medial JSW and lateral JSW in grade I and II showed that the medial and lateral knee joints have a similar distance. In the automatic, the average value of measurement lateral JSW in OA grades I and II was greater than the medial JSW.
\end{abstract}

Conclusion: Automatic measurements showed that both of medial and lateral JSW at grade II OA knee were narrower than the results at grade I. Automatic measurement of JSW results was more consistent than the manual measurement method.

Citation: Sugiyanto S, Fatimah F, Budi WS, Suwondo A, Suyanto H. Comparison of Joint Space Width Determinations in Grade I and II Knee Osteoarthritis Patients Using Manual and Automatic Measurements. J Biomed Phys Eng. 2021;11(5):613-620. doi: 10.31661/jbpe.v0i0.1912-1003.

\section{Keywords}

Grades; Joint Space; Measurements; Middle Aged; Radiotherapy; Osteoarthritis

\section{Introduction}

$0 \%$ of the world's population aged $\geq 60$ years old has osteoarthritis (OA). In the United States, $12.1 \%$ of the population of the United L States has clinical signs and symptoms of OA between the ages of $25-75$ years, going up to $70-90 \%$ at the age of $\geq 75$ years [1]. Moreover, $80 \%$ of British people aged $\geq 70$ years suffer from OA. According to a Norwegian study, more than $80 \%$ of the population was aged $\geq 55$ years and overall osteoarthritis prevalence was $12.8 \%$, which was higher in women $(14.7 \%)$ than men $(10.5 \%)$; in detail, osteoarthritis prevalence in the knee was 7.1\%; pelvic osteoarthritis was 5.5\%, and hand osteoarthritis was $4.3 \%$ [2]. In Thailand, the prevalence of OA, based on the results

${ }^{1}$ PhD, Radiology Technic Study Program, Department of Radiodiagnostic and Radiotherapy,

Poltekkes Kemenkes

Semarang, Indonesia

${ }^{2}$ MMed, Radiology Tech-

nic Study Program, De-

partment of Radiodiag-

nostic and Radiotherapy,

Poltekkes Kemenkes

Semarang, Indonesia

${ }^{3} \mathrm{PhD}$, Department of

Physics, Faculty of Math-

ematics and Natural

Science, Diponegoro

University, Semarang,

Indonesia

${ }^{4} \mathrm{MD}$, PhD, Depart-

ment of Public Health,

Faculty of Public Health

Program, Diponegoro

University, Semarang,

Indonesia

${ }^{5} \mathrm{MD}$, PhD, Post Gradu-

ate Program, Poltekkes

Kemenkes Semarang,

Indonesia

*Corresponding author:

Sugiyanto Sugiyanto

Radiology Technic Study

Program, Department

of Radiodiagnostic and

Radiotherapy, Poltekkes

Kemenkes Semarang,

Indonesia

E-mail: sugiyanto@kem-

kes.go.id

Received: 16 December 2019 Accepted: 4 February 2020 
of research on Buddhist monks was 59.4\% [3].

People who experience OA disorders in Indonesia encompass $8.1 \%$ of the total population. As many as $29 \%$ of them monitor their disease through doctor examinations and the rest, $71 \%$, directly consume pain medication to manage their OA. Based on the $2007 \mathrm{Ba}-$ sic Health Research report (RISKESDAS), the national prevalence for the joint disease was $30.3 \%$. The prevalence of osteoarthritis reached $5 \%$ at the age of $<40$ years, and $30 \%$ at the age of $40-60$ years, and $65 \%$ at the age of $>61$ years. The prevalence of knee osteoarthritis was quite high, $15.5 \%$ in men and $12.7 \%$ in women. According to the results of the study, 11 provinces have a prevalence of joint disease above the national percentage, including central Java, which reached 36.8\% (diagnosis and symptoms), and 12\% (diagnosis only) [4].

The development of digital radiography and optimization of standardized protocols cause it to be commonly used as a standard for structural evaluation because it is non-invasive, inexpensive, fast, and available at every radiology service clinic [5]. Radiographic examination to evaluate disease development and treatment will be improved if conducted in more detail with quantitative measurements $[5,6]$. The development of digital evaluation is possible as most radiology services have currently been using digital technology; the digital radiographic image can be observed directly on a computer or further analyses as needed.

Standard assessment of osteoarthritis degree from knee radiographic images is carried out based on the Kellgren and Lawrence (KL) grading system, which has two radiographic features, as follows: the presence or the absence of osteophytes and narrowing of the joint gap. The knee radiograph is to indicate $\mathrm{OA}$ if the KL grade is $\geq$ II, while grades 0 and I are normal [7].

The method of knee radiography examination to detect narrowing of the joint gap is generally with a visual estimation by measuring the joint gap (JSW) on the radiograph using a ruler. However, due to various factors such as high examination load, it is necessary to develop a method to measure the joint gap with more accurate and faster results. The use of digital radiography, such as Computed Radiography (CR) to produce digital images of the knee joint combined with computer programs for image processing has been previously studied. In some applications, the digital image of the knee joint is processed by quantitative measurement with a program called Knee Images Digital Analysis (KIDA). This method has been used in the Netherlands to examine the progress of OA based on radiographic parameters [5]. This method has not been used in Indonesia yet.

Researchers have made a Matlab-based measurement computer program called DIKA (Digital Image Knee Automatic assessment). This program is able to analyze the DICOM images from CR modality, widely used in Indonesia, as well as comparing the results of JSW measurements manually with computerbased measurements in OA patients with the patient standing in a weight-bearing position and evaluating the width of the joint gap or JSW, especially in patients with grade I or II OA. Grade I and II categories capture the transition between a normal state and OA, which is very crucial in the subsequent treatment.

\section{Material and Methods}

\section{Sample population}

This cross-sectional study was conducted using an analytic observational method. The sampling technique used was purposive, wherein the samples were taken with a specific purpose and objective. The study samples were patients with primary OA, aged between 46 and 65 years with KL grade I and II. This research was conducted after obtaining Ethical Clearance from Fakultas Kedokteran Undip KEPK - Dr. Kariadi Semarang No. 632 / EC / FK-RSDK / X / 2017, dated November 
Osteoarthritis Measurement between Manual and Automatic

2, 2017. Based on the inclusion criteria, 40 patients were obtained as samples. Each patient filled out and agreed to an informed consent sheet according to recommendations from the ethics committee. The recorded data of the patients included information about name, age, sex, BMI, and a history of diseases associated with joint pain, and also whether they have had joint surgery.

\section{Digital radiography}

Radiographic examination of the knee used CR. CR was performed with the patient standing anteroposterior projection (AP), bipedal weight-bearing with both knees placed in the middle of the film. The concentration was directed at the point between the knees with horizontal $\mathrm{x}$-rays as high as the inferior patella. Digital radiographs of right and left AP weight-bearing knee projections were assessed using KL grade by radiology specialists, then JSW was measured manually using a bar to determine the minimum medial and lateral JSW. The digital radiograph was also measured using a Matlab-based software program at vertical pixel spacing, which produced a minimum value of JSW (Oka, 2008), as seen in Figure 1, on medial and lateral JSW.

Researchers have designed a Matlab-based computer measurement program to assess OA criteria such as joint fissures, osteophyte area, height eminence and tibiofemoral angle (TFA). Joint cleft distance measurements were performed in the narrowest areas in the middle of the medial and lateral compartment of each knee automatically. The radiographic image was then analyzed by a radiologist to determine the grade, if grades other than I and II, then the patient was removed from this sample data. Data were then statistically analyzed using the Wilcoxon test and the Mann-Whitney test using SPSS 16.0, to see the difference in grades I and II, both measured manually and digitally.

As seen in Figure 1, the value of JSW was determined by automatic measurements from the narrowest JSW. This value was calculated by the shortest vertical length in the JSW area. This line was shown in the Figure 1 in purple and red; then the medial and lateral JSW values were obtained automatically.

\section{Results}

\section{Analysis of Patient Characteris- tics}

Patient data characteristics assessed were KL grade, sex, Body Mass Index (BMI), occupation, JSW medial-lateral manual and JSW medial-lateral automatic. There were no differences in the data characteristics of the patients in each group; $p$-values were $>0.05$ for sex $(p$-value $=0.433)$, body mass index ( -val$\mathrm{ue}=0.416)$ and occupation ( $\mathrm{p}$-value $=0.148)$.

The number of patients in the grade I and grade II groups was 14 people and 26 people, respectively. The sex of the patient had a frequency distribution of 13 men $(32.5 \%)$ and

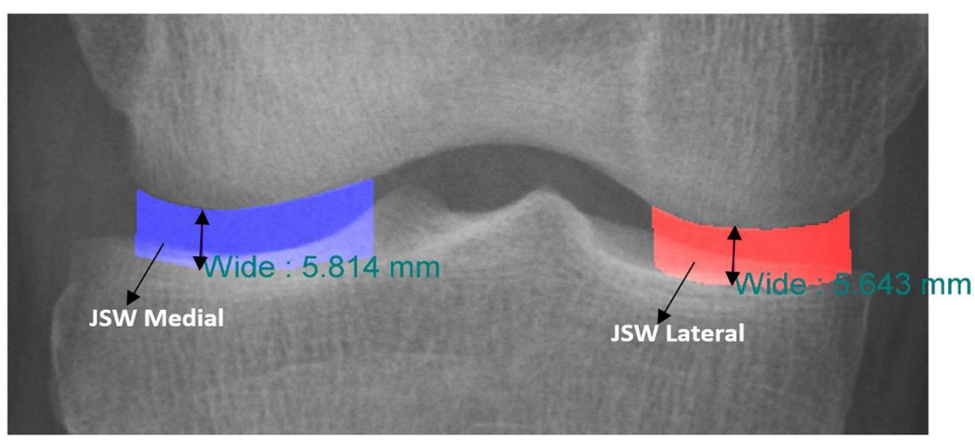

Figure 1: Automatic measurements of joint space width (JSW) medial and lateral JSW using Matlab-based computer program. 
27 women (67.5\%). BMI has a frequency distribution of normal $14(35 \%)$, overweight 14 $(35 \%)$ and obese $12(30 \%)$. The work has a frequency distribution of 14 employees (35\%), IRT $14(35 \%), 8$ pensioners $(20 \%), 1$ doctor $(2.5 \%)$ and entrepreneur $3(7.5 \%)$. The patient's average JSWs were as follows: manual medial (4.55 \pm 1.43$) \mathrm{mm}$, manual lateral (5.18 $\pm 1.04) \mathrm{mm}$, automatic medial $(4.82 \pm 0.55)$ $\mathrm{mm}$ and automatic lateral $(4.98 \pm 0.54) \mathrm{mm}$.

\section{Bivariate Analysis}

Bivariate analysis was carried out to test differences in the measurement of JSW mediallateral measured manually and the automatic measurement of JSW medial-lateral. This bivariate analysis was carried out on JSW medial-lateral for OA knee grade I and grade II with manual and automatic measurement.

As seen in Table 1, manual JSW Medial measurements had a mean, at grade I, of 4.47 $\pm 1.19 \mathrm{~mm}$ and at grade II, $4.60 \pm 1.58 \mathrm{~mm}$. The manual measurement of lateral JSW had a mean at grade I of $5.00 \pm 1.13 \mathrm{~mm}$ and at grade II, of $5.28 \pm 0.98 \mathrm{~mm}$. The automatic JSW medial measurements had a mean, at grade I, of $5.33 \pm 0.49 \mathrm{~mm}$ and at grade II, of $4.50 \pm 0.30$ $\mathrm{mm}$, while automatic lateral JSW measurements had an average at grade I of $5.51 \pm 0.39$ $\mathrm{mm}$, and at grade II, of $4.65 \pm 0.30 \mathrm{~mm}$.

In the JSW medial group, there were significant differences between the measurement of JSW medial manually and automatically in grade I, with a p-value of 0.047 , but there was no difference in grade II, with a p-value of 0.716. In the lateral JSW group, there were no differences in manual and automatic lateral JSW measurements of OA knee in grade I with a $\mathrm{p}$-value of 0.073 , whereas there was a significant difference in grade II with a p-value of 0.005 .

As seen in Table 2, there was no difference in the manual measurements of JSW medial and JSW lateral in grade I and grade II with a p-value of 0.605 , and a p-value of 0.344 , respectively. Whereas in the automatic measure-

Table 1: Paired differences test results on joint space width (JSW) medial-lateral measurements of grade $I$ and grade 2 knee osteoarthritis $(O A)$, with manual and automatic measurements.

\begin{tabular}{ccccc} 
Variable & Grade & Manual & Automatic & p-value \\
\hline \multirow{2}{*}{ JSWMed } & I & $4.47 \pm 1.19$ & $5.33 \pm 0.49$ & 0.047 \\
\cline { 2 - 5 } & II & $4.60 \pm 1.58$ & $4.50 \pm 0.30$ & 0.716 \\
\hline \multirow{2}{*}{ JSWLat } & I & $5.00 \pm 1.13$ & $5.51 \pm 0.39$ & 0.073 \\
\cline { 2 - 5 } & II & $5.28 \pm 0.98$ & $4.65 \pm 0.30$ & 0.005
\end{tabular}

Table 2: The results of the unpaired difference test were based on the grade of the JSW mediallateral measurement of grade I and grade II osteoarthritis (OA) knee.

\begin{tabular}{cccc} 
Variable & Grade & Descriptive & p-value \\
\cline { 2 - 3 } JSWMed & I & $5(3-7)$ & \multirow{2}{*}{0.605} \\
\cline { 2 - 3 } & $\|$ & $5(1-7)$ & \multirow{2}{*}{0.344} \\
\cline { 2 - 3 } JSWLat & I & $5(3-7)$ & \multirow{2}{*}{$<0.001$} \\
\cline { 2 - 3 } JSWMed Automatic & I & $5.59(4.26-5.76)$ & \multirow{2}{*}{$<0.001$}
\end{tabular}


Osteoarthritis Measurement between Manual and Automatic

ment of JSW medial and lateral JSW, there was a difference in grades I and grades II with p-values of $<0.001$ in both.

\section{Data Distribution Analysis}

A comparison of the distribution of patient data between manual JSW medial and lateral measurements in OA knee grade I and grade II can be seen in Figure 2 A and B.

Statistical analysis of the data distribution of patients, shown in Figure 2, can be seen in Table 3.

It can be seen that the average range of grades I was $4.5-4.90 \mathrm{~mm}$, while grade II was $4.75-5.13 \mathrm{~mm}$ (Table 3 ). In grade I and II, both have a minimum value of $3 \mathrm{~mm}$ and a maximum of $7 \mathrm{~mm}$. The results of manual and lateral measurements of JSW medial OA knee grade II were wider than the results of JSW measurements in grade I. Comparison of the patient data distribution between JSW medial and lateral automatic measurements in OA knee grade I and grade II can be seen in Figure $3 \mathrm{~A}$ and $\mathrm{B}$.

Figure 3 shows the results of data distribution between the automatic measurement of JSW medial and lateral of OA knee grade I and grade II. Statistical analysis of the patient data distribution can be seen in Table 4.

In Table 4, it can be seen that the average range in grade I was $5.34-5.59 \mathrm{~mm}$, while in grade II was $4.65-4.85 \mathrm{~mm}$. In grade I, it has a medmin value of $4.66 \mathrm{~mm}$, and latmin of 4.92 $\mathrm{mm}$, and medmax of $5.76 \mathrm{~mm}$, and latmax of
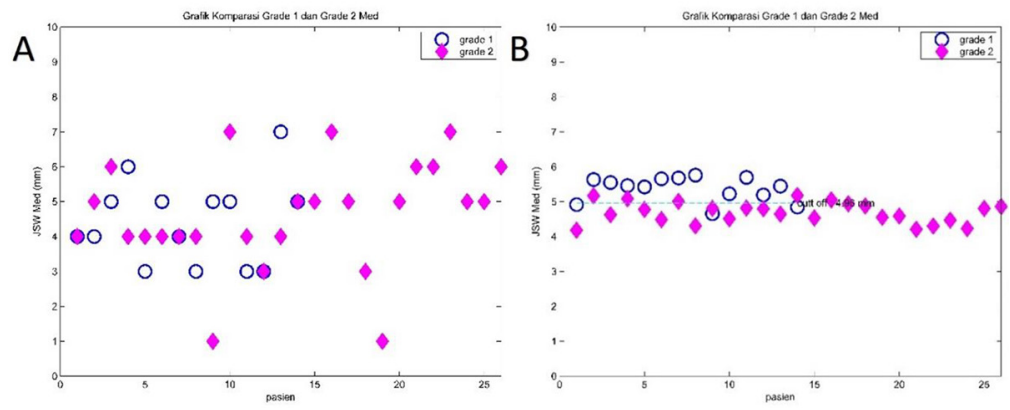

Figure 2: The data distribution between the measurement of or joint space width (JSW) medial osteoarthritis (OA) knee grade I and grade II (A) manual and (B) automatic.

Table 3: Statistical analysis of data distribution between the manual measurement of or joint space width (JSW) medial and lateral osteoarthritis (OA) knee at grade I and grade II.

\begin{tabular}{ccc} 
Grade I & Med $(\mathbf{m m})$ & Lat $(\mathbf{m m})$ \\
\hline Avg & 4.50 & 4.90 \\
\hline Std & 1.07 & 0.96 \\
\hline Min & 3.00 & 3.00 \\
\hline Max & 7.00 & 7.00 \\
\hline Grade II & & \\
\hline Avg & 4.75 & 5.13 \\
\hline Std & 1.44 & 1.13 \\
\hline Min & 3.00 & 3.00 \\
\hline Max & 7.00 & 7.00
\end{tabular}

$5.96 \mathrm{~mm}$. In grade II, it has a medmin value of $4.18 \mathrm{~mm}$, and latmin of $4.11 \mathrm{~mm}$, and medmax of $5.18 \mathrm{~mm}$, and latmax of $5.49 \mathrm{~mm}$. The results of the automatic medial and lateral JSW measurements of grade II OA knee are narrower than grade I.

\section{Discussion}

In this study, patients were mostly women $(67.5 \%)$ aged between 46 and 65 years, the majority with OA knee grade II $(65 \%)$ rather than grade I $(35 \%)$. This is consistent with previous studies, in which OA knee is suffered by many female patients in that age range, especially over 40 years old because OA is a degenerative disease, where age is a dominant 


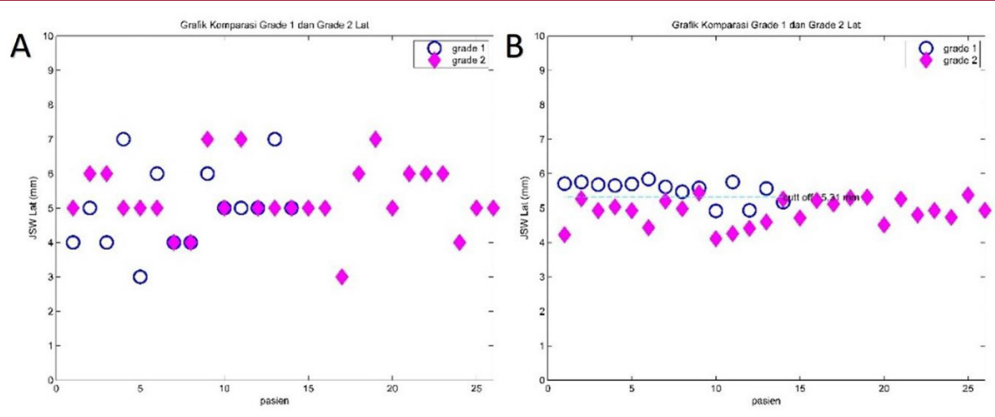

Figure 3: The data distribution between the manual measurement of or joint space width (JSW) lateral osteoarthritis (OA) knee (A) grade I and (B) grade II.

Table 4: Statistical analysis of the data distribution between the automatic measurement of or joint space width (JSW) medial and lateral in osteoarthritis (OA) knee at grade I and grade II.

\begin{tabular}{ccc} 
Grade I & Med $(\mathbf{m m})$ & Lat $(\mathbf{m m})$ \\
\hline Avg & 5.34 & 5.59 \\
\hline Std & 0.32 & 0.27 \\
\hline Min & 4.66 & 4.92 \\
\hline Max & 5.76 & 5.96 \\
\hline Grade II & & \\
\hline avg & 4.65 & 4.85 \\
\hline std & 0.30 & 0.40 \\
\hline min & 4.18 & 4.11 \\
\hline max & 5.18 & 5.49
\end{tabular}

factor [8-10].

In this study, researchers focused on osteoarthritis patients with grade I and grade II based on the evaluation of KL grade criteria from a radiologist [11]. There are 5 grades in the KL grading scale. Grade 0 and grade I are normal, meaning that the patient has not experienced osteoarthritis, while for grade II or more it is stated that the patient has osteoarthritis. Some previous studies characterized the distribution of all grades, but here the authors only focused on patients with grade I and grade II. Determining the boundary between grades I and II is crucial to diagnosing whether the patient has osteoarthritis [12-14]. Another thing motivating this choice is that if the diagnosis can be done earlier, patients can get the right therapy and will not suffer from more severe osteoarthritis.

The procedure to take a picture in this study uses AP bipedal weight-bearing projections position, with a center-point concentration between the right and left knees as high as the inferior patella. In previous studies, the examination of knee radiographs with AP weightbearing projections showed that there was a difference in the narrowing of JSW compared to knee radiographic examinations performed with the position of laying patients [15]. Based on studies in the UK, there is no consensus about the proper positioning of patients in photographs for OA [16]. Out of $86 \%$ of requests for knee weight bearing photos, only $12 \%$ of patients do the knee flexed projections [17]. Several studies also mentioned that the best knee photoshoot used PA weight-bearing knee flexed projections to show the presence of tibiofemoral arthrosis. However, here the researchers did not use these projections because OA patients will generally experience pain when they have to stand up with legs bent. Besides, in almost all hospitals, if there is a request for knee photographs, it will be done using AP bipedal weight-bearing projections. Another study states that there is no significant difference between a bipedal weight-bearing AP (with both legs resting) and a mono pedal weight-bearing AP (standing on one leg resting) on the JSW measurement results [18].

JSW or joint space width is a joint gap formed 
by the distal femur and the proximal tibia. One of the earliest signs is narrowing the joints, especially in the medial compartment that can be used indirectly to see the thinning of joint cartilage. The depletion of joint cartilage is a primary indicator of OA and one of the early signs of disease progression. If the joint cartilage is damaged during the OA pathogenesis process, the thickness of the cartilage will decrease so that the joint space width will also be reduced. Thus, the JSW radiographic picture is very useful for assessing the presence or absence of joint OA, the progress of OA itself, and to evaluate the efficacy of chondroprotection drug administration. Examination using radiography is cheaper and widely accepted by the public. OA research by Visser et al. (2000) also used conventional radiographic examinations with almost 48,000 radiographic images [16]. Radiographic images also produce better resolution than other modalities and can show a clear picture of bone boundaries. Radiographic images can also be used to calculate the narrow width of JSW either manually or automatically by the computer $[19,20]$.

In this study, manual measurement using a ruler was done by connecting the outermost points of each femur and tibia. The computer was used to automatically calculate and find the narrowest area in each joint by blocking the medial area and lateral compartment. The automatic calculation was based on the calculation of the number of pixels. Based on both measurements, the medial JSW was narrower than the lateral JSW in automatic measurements. With manual measurement, the results were different where lateral JSW was narrower than medial JSW. Some previous studies state that the medial JSW is narrower than the lateral JSW because it receives more weight from the body when doing more activity on the medial side of the genu compartment [10, $13,19,21]$.

The results of manual measurements are different from some of the automatic measures in this study because manual measurement re- quires accuracy and patience. If there are many patient examinations on that day, it may result in fatigue and rushed examination processes, especially during measurements with a ruler that can become less precise (Figures 2 and 3). Manual measurements appear to be more variable in distribution compared to automatic measurements. Different results are shown in studies in manual measurement using a ruler (millimeters), producing reproducible measurements on the joint space width of the knee radiographic image [22]. However, together with the development of the digital era, where almost all radiographs produce digital images, the calculations using a caliper or automatic measurement with a computer program can be easier and feasible.

In this study, it is clear that there is a significant difference in automatic measurement of medial JSW and lateral JSW in grade II, which is narrower than in medial and lateral JSW in grade I. Based on Kelgreen and Lawrence grading, grade II is clear if there is a narrowing of JSW and osteophytes appearance. Meanwhile, manual measurement in grade II medial JSW and lateral JSW is wider than grade I. Rheumatologists prefer to use grading with KL grading to confirm the presence or absence of osteophytes. According to previous study, knee osteoarthritis is diagnosed using the presence or absence of marginal osteophytes [23]. While the progress of osteoarthritis development must be evaluated, including the narrowing of JSW, the presence or absence of sub-chondral sclerotics, and the presence of subchondral cysts. Poor alignment of ipsilateral lower limbs can be a risk factor for osteophytes. In further research, it is also necessary to investigate the presence or absence, the number and extent of osteophytes in addition to the narrowing of JSW.

\section{Conclusion}

The automatic measurements of medial and lateral JSW in grade II OA knee were narrower than JSW in grade I. Automatic JSW measure- 
ment results are more accurate than manual measurements.

\section{Acknowledgment}

The author thanks the Director of RSUP Dr. Kariadi Semarang, Head of Radiology Installation RSUP Dr. Kariadi Semarang Hospital, and Head of the Department of Radiodiagnostic and Radiotherapy, Poltekkes Kemenkes Semarang, Indonesia.

\section{Conflict of Interest}

\section{None}

\section{References}

1. Woolf AD, Pfleger B. Burden of major musculoskeletal conditions. Bulletin of the World Health Organization. 2003;81:646-56.

2. Østerås N, Risberg MA, Kvien TK, et al. Hand, hip and knee osteoarthritis in a Norwegian population-based studyThe MUST protocol. BMC Musculoskeletal Disorders. 2013;14(1):201. doi: 10.1186/1471-2474-14-201.

3. Tangtrakulwanich B, Geater AF, Chongsuvivatwong V. Prevalence, patterns, and risk factors of knee osteoarthritis in Thai monks. Journal of Orthopaedic Science. 2006;11(5):439. doi: 10.1007/s00776-006-1040-y. PubMed PMID: 17013729.

4. Republic Indonesian Health Department. Laporan Riset Kesehatan Dasar (Riskesdas). Basic Health Research Report; 2007. Available from: https://www.litbang.kemkes. go.id/laporan-riset-kesehatan-dasar-riskesdas/.

5. Kinds MB, Marijnissen AC, Bierma-Zeinstra SM, et al. Detection of progression of radiographic joint damage in case of very early osteoarthritis: sensitivity to change of quantitative analysis compared to qualitative grading. Rheumatology Reports. 2012;4(1):e9. doi: 10.4081/ rr.2012.e9.

6. Budi WS, Suwondo A. Measurement of Joint Space Width and Tibiofemoral Angle Using a Digital Image Processing for Predicting Knee Osteoarthritis. Advanced Science Letters. 2017;23(7):6598-600. doi: 10.1166/asl.2017.9692.

7. Kohn MD, Sassoon AA, Fernando ND. Classifications in brief: Kellgren-Lawrence classification of osteoarthritis. Clin Orthop Relat Res. 2016;474(8):1886-93. doi: 10.1007/s11999-016-4732-4. PubMed PMID: 26872913. PubMed PMCID: PMC4925407.

8. Ahmad IW, Rahmawati LD, Wardhana TH. Demographic profile, clinical and analysis of osteoarthritis patients in Surabaya. Biomolecular and Health Science Journal. 2018;1(1):34-9. doi: 10.20473/bhsj.v1i1.8208.

9. Galli M, De Santis V, Tafuro L. Reliability of the Ahlbäck classification of knee osteoarthritis. Osteoarthritis and Cartilage. 2003;11(8):580-4. doi: 10.1016/S10634584(03)00095-5. PubMed PMID: 12880580.

10. Anas I, Musa TA, Kabiru I, Yisau AA, et al. Digital radiographic measurement of normal knee joint space in adults at Kano, Nigeria. The Egyptian Journal of Radiology and Nuclear Medicine. 2013;44(2):253-8. doi: 10.1016/j. ejrnm.2013.03.005.

11. Kellgren $\mathrm{JH}$, Lawrence $\mathrm{J}$. Radiological assessment of osteo-arthrosis. Ann Rheum Dis. 1957;16(4):494-502. doi: 10.1136/ard.16.4.494. PubMed PMID: 13498604. PubMed PMCID: PMC1006995.

12. Duren DL, Sherwood RJ, Chumlea WC, Siervogel RM, Towne B. Radiographic joint space of the knee in healthy young adults. Human Biology. 2006;78(3):353-64. doi: 10.1353/hub.2006.0042. PubMed PMID: 17216807.

13. Jain RK, Jain A, Mahajan P. Radiographic evaluation of knee joint space width using fixed flexion view in knees of Indian adults. International Journal of Research in Orthopaedics. 2019;5(1):38. doi: 10.18203/issn.2455-4510. IntJResOrthop20184730.

14. Messieh SS, Fowler PJ, Munro T. Anteroposterior radiographs of the osteoarthritic knee. $J$ Bone Joint Surg Br. 1990;72(4):639-40. doi: 10.1302/0301-620X.72B4.2380220. PubMed PMID: 2380220.

15. Leach RE, Gregg T, Siber FJ. Weight-bearing radiography in osteoarthritis of the knee. Radiology. 1970;97(2):265-8. doi: 10.1148/97.2.265. PubMed PMID: 5481130.

16. Visser $M$, Newman $A B$, Nevitt $M C$, et al. Reexamining the sarcopenia hypothesis: Muscle mass versus muscle strength. Health, Aging, and Body Composition Study Research Group. Ann N Y Acad Sci. 2000;904:456-61. doi: 10.1111/j.1749-6632.2000.tb06500.x. PubMed PMID: 10865789

17. Bhatnagar S, Carey-Smith R, Darrah C, et al. Evidencebased practice in the utilization of knee radiographs-a survey of all members of the British Orthopaedic Association. Int Orthop. 2006;30(5):409-11. doi: 10.1007/s00264006-0099-6. PubMed PMID: 16642345. PubMed PMCID: PMC3172767.

18. Albuquerque RP E, Barbosa C, Melquíades D, et al. Comparative analysis between radiographic views for knee osteoarthrosis (bipedal AP versus monopedal AP). Revista Brasileira De Ortopedia. 2013;48(4):330-5. doi: 10.1016/j. rbo.2012.06.006.

19. Dacre JE, Scott DL, Da Silva JA, et al. Joint space in radiologically normal knees. Br J Rheumatol. 1991;30(6):4268. doi: 10.1093/rheumatology/30.6.426. PubMed PMID: 1747696

20. Duryea J, Li J, Peterfy CG, Gordon C, Genant HK. Trainable rule-based algorithm for the measurement of joint space width in digital radiographic images of the knee. Medical Physics. 2000;27(3):580-91. doi: 10.1118/1.598897. PubMed PMID: 10757609.

21. Sargon MF, Taner D, Altintaş K. Examination of joint space by magnetic resonance imaging in anatomically normal knees. Clin Anat. 1996:9(6):386-90. doi: 10.1002/ (SICI)1098-2353(1996)9:6<386::AID-CA5>3.0.C0;2-9. PubMed PMID: 8915618.

22. Ravaud P, Chastang C, Auleley GR, et al. Assessment of joint space width in patients with osteoarthritis of the knee: a comparison of 4 measuring instruments. The Journal of Rheumatology. 1996;23(10):1749. PubMed PMID: 8895153.

23. Markhardt BK, Li G, Kijowski R. The clinical significance of osteophytes in compartments of the knee joint with normal articular cartilage. American Journal of Roentgenology. 2018;210(4):W164-71. doi: 10.2214/AJR.17.18664. PubMed PMID: 29470158. PubMed PMCID: PMC6334768. 